\title{
CAPITALISMO, QUESTÃO AGRÁRIA E OS MOVIMENTOS SOCIAIS.
}

João Mateus de Amorim ${ }^{1}$

(1 - Professor de Geografia - Escola Agrotécnica Federal de Uberlândia, mateusamorim@terra.com.br)

\section{Resumo}

Este artigo faz uma abordagem do capitalismo, da questão agrária e dos movimentos sociais do campo brasileiro; também permitirá estabelecer possíveis discussões, com vistas ao entendimento das ações humanas sobre o espaço rural. $\mathrm{O}$ viés de discussão deste trabalho abordará a luta pela terra e pela reforma agrária com o intuito de resgatar a dignidade dos expropriados do campo. O capitalismo, o latifúndio, as políticas de créditos voltadas, somente, para as oligarquias rurais são os principais ingredientes da questão agrária no país, no qual faz parte de um conjunto de situações que envolvem o espaço rural brasileiro. Um dos caminhos para resolver a questão agrária brasileira é rever as políticas públicas de Estado, o contexto econômico, a estrutura fundiária e o grau de participação dos trabalhadores e, ao vencermos as barreiras desta questão é necessário concretizar a reforma agrária.

Palavras chave: Reforma Agrária, Questão Agrária, Movimentos Sociais.

\section{Abstract}

\section{CAPITALISM, AGRARIAN QUESTION AND THE SOCIAL MOVEMENTS.}

This article makes a boarding of the capitalism, the agrarian question and the social movements of the Brazilian field. This boarding also will allow establishing possible quarrels, with sights, to the agreement of the actions human beings on the agricultural space. The bias of quarrel of this work is it will approach in the fight for the land and the agrarian reform with intention to rescue the dignity of the expropriated ones of the field. The capitalism, the privilege of the large state, the modernization, the industrialization and the politics of state directed toward the agricultural oligarchies are the main ingredients of the agrarian question in the country. The agrarian question is a set of situations that involve the Brazilian agricultural space. To decide the Brazilian agrarian question we will have that to review the politics public of State, the economic context, the agrarian structure and the degree of 


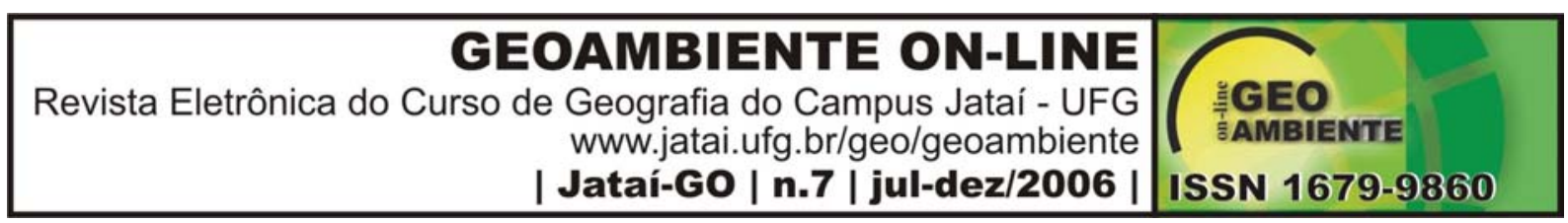

participation of the workers, and when being successful these barriers and that we would have possibility to materialize the agrarian reform.

Key Words: Agrarian Reform, Agrarian Question, Social Movements.

\section{Introdução}

Na fundação do MST (Movimentos dos Trabalhadores sem Terra) os trabalhadores construíram um novo espaço no cenário político brasileiro da luta pela terra. Um ano depois, em janeiro de 1985, na cidade de Curitiba - PR, o MST realizou o primeiro congresso nacional dos trabalhadores sem-terra [...] (FERNANDES, 1999: 80). A luta pela terra e pela reforma agrária, mudou-se os aspectos políticos, mas não houve alteração nos aspectos econômicos no Brasil com uma ampla reforma agrária. Essa mudança torna-se difícil devido a relação entre poder político e econômico das oligarquias rurais referenciada na bancada ruralista no congresso e de um número considerável de governantes do poder executivo aliados nesta relação.

Um movimento socioterritorial como o MST tem como um de seus principais objetivos a conquista da terra de trabalho. E o realiza por meio de uma ação denominada ocupação da terra. A ocupação é um processo socioespacial e político complexo que precisa ser entendido como forma de luta popular de resistência do campesinato, para sua recriação e criação. A ocupação desenvolve-se nos processos de espacialização e territorialização, quando são criadas e recriadas as experiências de resistência dos sem-terra [...] são os trabalhadores desafiando o Estado, que sempre representou os interesses da burguesia agrária e dos capitalistas em geral. Por essa razão, o Estado só apresenta políticas para atenuar os processos de expropriação e exploração, sob intensa pressão dos trabalhadores [...] a organização de uma ocupação decorre da necessidade de sobrevivência [...] (FERNANDES, 2001: 52-53).

.A política de assentamentos minimiza as ocupações e os conflitos de forma localizada, sem o intuito de fazer reforma agrária, no sentido amplo. A luta pela terra é mais ampla, pois abrange as questões agrícolas, agrárias, políticas e de qualidade de vida das populações urbanas e rurais através do acesso a um pedaço de terra no espaço rural. 


\section{GEOAMBIENTE ON-LINE \\ Revista Eletrônica do Curso de Geografia do Campus Jataí - UFG www.jatai.ufg.br/geo/geoambiente \\ | Jataí-GO | n.7 | jul-dez/2006 | \\ IGEO \\ 今.AMBIENTE \\ ISSN 1679-9860}

[...] a luta pela terra não é, evidentemente, uma política do governo, mas sim dos trabalhadores. Sem reforma agrária, a implantação dos assentamentos tornou-se a política do governo [...] o assentamento não será o fim da luta, mas sim o território do início de novas lutas, e porque pelas experiências históricas e consciência política os sem-terra sabem que só colherão o que plantarem [...] a morte da luta também significa a morte de quem luta. (FERNANDES, 2001: 2).

"No capitalismo, o processo de produção do espaço social determinam as suas formas por meio das relações sociais, que são compreendidas na tríade ${ }^{1}$ formada pelo capital, trabalho assalariado e propriedades fundiárias" [...] (FERNANDES, 1999: 24). Neste contexto o espaço para a reforma agrária é bem restrito, no qual o capital requer a propriedade fundiária através do dinheiro e o serviço do trabalhador assalariado, ou seja, o trabalhador rural. Os países desenvolvidos adotaram a pequena agricultura como forma de ocupação do espaço rural, os países subdesenvolvidos o paraíso dos latifúndios e a expropriação de milhões de trabalhadores rurais sem-terra. Isso deu sustentação a uma grande desigualdade social e, enfim um pequeno mercado consumidor com um baixo desenvolvimento social e econômico.

Os capitalistas que hoje ostentam os melhores indicadores de desenvolvimento humano, dos Estados Unidos ao Japão, apresentam um traço comum: a forte presença da agricultura familiar, cuja evolução desempenhou um papel fundamental na estruturação de economias mais dinâmicas e de sociedades mais democráticas e eqüitativas. A expansão e dinamismo da agricultura familiar basearam-se na garantia do acesso à terra que em cada país assumiu uma forma particular, desde a abertura da fronteira oeste americana aos 'farmers' até a reforma agrária compulsória na Coréia e em Taiwan [...] a agricultura familiar desempenhou um papel estratégico [...] o de garantir uma transição socialmente equilibrada entre uma economia de base rural pra uma economia urbana e industrial (GUANZIROLI. et.al, $2001:$ 15).

O desenvolvimento perpassa os aspectos econômicos, sociais, culturais e ambientais e, para que haja equilíbrio no campo será necessária uma maior distribuição da terra, ou seja, a exploração agrícola com base na pequena agricultura familiar. Já para os países com a

\footnotetext{
${ }^{1}$ A tríade com base no capital, trabalho assalariado e na propriedade fundiária restringe-se ao máximo a idéia da ampla reforma agrária. Esse processo está preocupado somente com a questão agrícola e não com a questão agrária, que é a divisão das terras com qualidade de vida para todos os cidadãos no campo.
} 


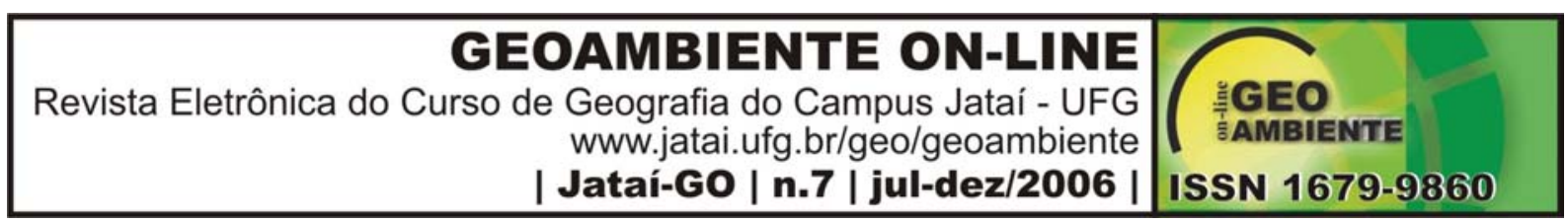

concentração fundiária teremos a presença do latifúndio e conseqüentemente o aumento dos trabalhadores sem-terra, dos conflitos fundiários, das ocupações e da pobreza tanto no campo como na cidade.

\section{O capitalismo e a Questão Agrária}

A questão agrária envolve os aspectos sociais, políticos, econômicos, e também abrange a luta pela terra e pela reforma agrária, enquanto que a questão agrícola é mais restrita a produção no campo.

A questão agrária é o movimento do conjunto de problemas relativos ao desenvolvimento da agropecuária e das lutas de resistência dos trabalhadores, que são inerentes ao processo desigual e contraditório das relações capitalistas de produção [...] os problemas referentes à questão agrária estão relacionados, essencialmente, à propriedade da terra, conseqüentemente à concentração da estrutura fundiária; aos processos de expropriação, expulsão e exclusão dos trabalhadores rurais: camponeses e assalariados; à luta pela terra, pela reforma agrária e pela resistência na terra; à violência extrema contra os trabalhadores, à produção, abastecimento e segurança alimentar; aos modelos de desenvolvimento da agropecuária e seus padrões tecnológicos, às políticas agrícolas e ao mercado, ao campo e à cidade, à qualidade de vida e dignidade humana [...] a questão agrária compreende as dimensões econômica, social e política (FERNANDES, 2001: 2324).

Guanziroli (2001) destaca-se que a partir da década de 1980 ocorre uma modernização na agricultura mais integrada aos capitais industriais, comerciais e financeiros surgindo aí os “complexos agropecuários". Sendo que, só haverá espaço dentro desse quadro em análise para a reforma agrária integrada à "agroindústria alimentar" ou inserida com a adoção de "pacotes tecnológicos".

[...] nos anos 70, o processo de modernização agrícola substituíra o crescimento extensivo (pela incorporação de terra e mão-de-obra); nos anos 80 , este processo de modernização aprofundara a integração da agricultura com os capitais industriais, comerciais e financeiros que a envolvem, formando o que foi chamado de "complexos agroindustriais". Dentro desse quadro analítico, mais do que nunca a reforma agrária passa a ser vista como economicamente sem sentido. Para ser competitivo e sobreviver, sobretudo na produção de commodities, era preciso adotar o novo "pacote" tecnológico, o 


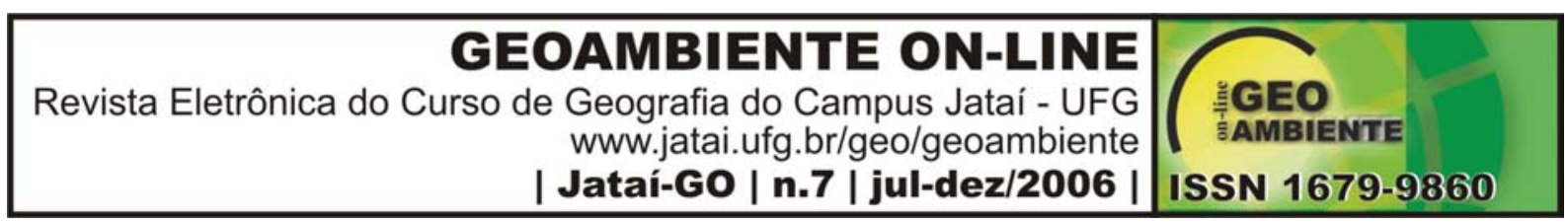

que exigia elevados investimentos, bem como possuir uma área mínima relativamente grande. As alternativas disponíveis para a pequena produção familiar se restringiriam a nichos de mercado ou à integração com a indústria agroalimentar [...] (GUANZIROLI. et.al, 2001: 33).

Reforma agrária, só se concretizará com políticas públicas de Estado e com a participação dos trabalhadores sem-terra, pois o contrário terá distribuição de terras pelo mercado fundiário de terras.

O Brasil destaca-se entre os países onde esta estratégia urbana de desenvolvimento resulta em um desastre social de grandes proporções. Tanto mais chocante por causa da enorme disponibilidade de terras ociosas, as quais poderiam ter sido apropriadas pelos pequenos produtores familiares sem ameaçar a expansão das áreas ocupadas produtivamente pelos produtores comerciais não-familiares. O país ostenta os piores indicadores de desenvolvimento humano [...] tornando um caso paradigmático de desenvolvimento desigual [...] (GUANZIROLI. et.al, 2001p.17).

Para Guanziroli (2001) as estratégias urbanas de desenvolvimento rural com base no "status" e no poder econômico dos latifundiários trazem à tona um baixo indicador de desenvolvimento humano com grandes desigualdades sociais e, por conseguinte, o aumento dos conflitos agrários e da marginalização de uma imensa massa de trabalhadores sem-terra.

A adoção de estratégias urbanas de desenvolvimento rural, que implicaram o abandono do segmento da agricultura familiar, se explica por razões políticas e econômicas específicas a estes países, em geral relacionadas ao poder das oligarquias rurais em manter um "status quo" marcado pela alta concentração dos recursos fundiários (GUANZIROLI. et.al, 2001: 16).

Segundo Guanziroli et.al (2001) as confluências de interesses entre as elites rurais e urbanas no Brasil, são:

- Proteção da propriedade da terra;

- introdução de inovações tecnológicas em consonância com as indústrias de insumos e equipamentos agrícolas instalados no final da década de 1950 e começo da década de 1960 ; 


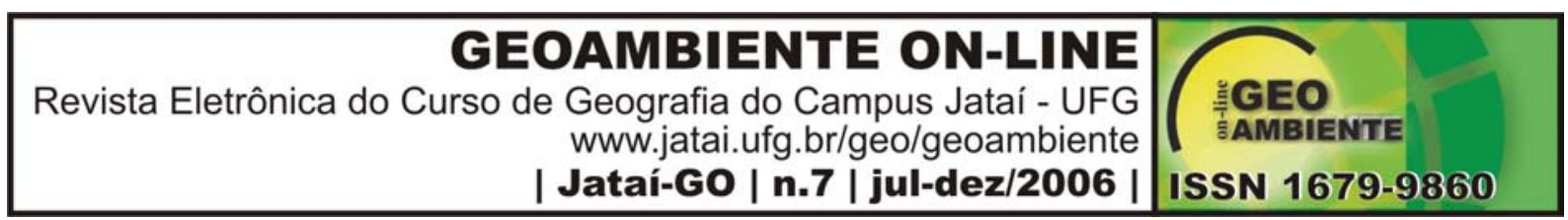

- redução da dependência em relação ao trabalho assalariado temporário (bóia-fria) pelas oligarquias rurais, trocando-os por máquinas e insumos químicos.

[...] a integração do latifúndio à economia moderna por intermédio da tecnificação seria suficiente para assegurar que a agricultura desempenhasse suas funções e para dinamizar a economia rural. Em nenhum momento levaram-se em consideração as conseqüências socioeconômicas e políticas da adoção desta estratégia, em particular sobre a distribuição de renda, tal era a confiança na leitura teórica que colocava todas as expectativas na indústria como dínamo do crescimento, e nas cidades como lócus de desenvolvimento (GUANZIROLI. et.al, 2001: 16).

Então, fica clara a dificuldade em fazer a reforma agrária deslocada do contexto capitalista, pois na medida em que avançamos na agricultura com o intuito de aumentar a produção e sua integração com a agroindústria alimentar através da pesquisa, do aumento de insumos, da tecnificação, do aspecto econômico e na preocupação com o "status" do produtor fica cada vez mais impossível construir uma reforma agrária com base na qualidade de vida, na sobrevivência e na resolução da questão agrária de forma ampla.

A questão agrária é um elemento estrutural do capitalismo. Portanto, o conjunto de problemas é constante, pode-se amenizá-las, diminuir suas escalas, mas não é possível solucioná-los totalmente. Políticas públicas são medidas possíveis para amenizar a intensidade dos problemas [...] outras possibilidades são as formas de lutas dos trabalhadores, por meio da pressão política: as ocupações de terra, as marchas, as ocupações de prédios públicos, as greves etc. Essas são ações que modificam a conjuntura, mas não impedem o processo de intensificação das desigualdades, geradoras da miséria e da fome. A persistência do movimento e a inovação dos problemas são próprias da lógica em questão (FERNANDES, 2001: 24).

A questão agrária abrange desde a produção agrícola até as condições socioeconômicas dos produtores no campo, enquanto que a questão agrícola é mais restrita ao aumento da produção e os aspectos econômicos. Para resolver esta situação torna-se necessário o aumento de políticas de Estado. A análise da questão agrária e da luta pela terra deve estar atrelada ao aumento da qualidade de vida tanto nos aspectos sociais, ambientais, culturais e econômicos. 


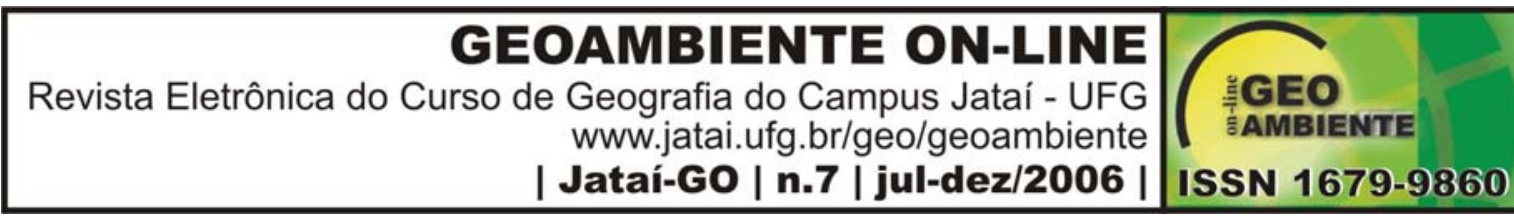

Pelo fato de a questão agrária ser um conjunto de problemas inerentes ao capitalismo, para serem amenizados é necessário que se realizem simultaneamente medidas de caráter político e socioeconômico [...] somente as lutas pela terra e pela reforma agrária não são suficientes para amenizar os problemas [...] apenas as políticas governamentais também não são suficientes. A questão não é só a distribuição da terra, mas também construir novas relações de poder com a participação dos trabalhadores na efetivação das políticas públicas [...] políticas públicas eficazes se efetivam com a participação dos trabalhadores (FERNANDES, 2001: 24).

Avaliando a questão agrária no todo com base na visão holística fica evidente que se resolve essa questão se vencer as barreiras do capitalismo, do Estado e da participação política dos envolvidos no processo. E que só com o envolvimento de uma das partes trata-se de pequenas reformas estruturais, então para solucionar a reforma agrária de uma forma ampla há a necessidade da inter-relação entre as três partes envolvidas. O que acontece no Brasil é uma distribuição de terras (assentamentos e acampamentos) via Estado em conjunto com as oligarquias rurais pressionadas pelos movimentos sociais dos trabalhadores Sem-Terra.

A luta pela terra é uma importante dimensão da questão agrária [...] a amplitude dessa luta é conhecida por diversas manifestações cotidianas dos sem-terra, desde o trabalho de base às ocupações de terra; do enfrentamento aos latifúndios às diversas formas de violência contra os sem-terra; dos acampamentos e dos protestos com ocupações de prédios públicos às intermináveis negociações com o governo; do assentamento à demanda por política agrícola, na formação da consciência de outros direitos básicos, como educação, saúde etc. (FERNANDES, 2001: 37).

O Estado tenta desmobilizar os movimentos sociais via militarização, judiciarização e através da doação de terras. Os assentamentos, no Brasil, são frutos das ocupações, das passeatas, dos enfrentamentos com o Estado, com a polícia, com a justiça e com os jagunços do latifúndio no campo. A luta pela terra perpassa por toda esta situação de resistência, de violência, de exclusão e da conquista por um pedaço de terra nestes assentamentos desestruturados, localizados, isolados, e na maior parte, produtos de uma política distributiva de terras, de cunho capitalista, de reserva de mão-de-obra para as elites do campo e espaço concentrador de um imenso bolsão de miséria no campo.

\section{Reforma Agrária ou Assentamento de Terras}




\section{GEOAMBIENTE ON-LINE \\ Revista Eletrônica do Curso de Geografia do Campus Jataí - UFG www.jatai.ufg.br/geo/geoambiente \\ | Jataí-GO | n.7 | jul-dez/2006 || \\ 틍 \\ 亏AMBIENTE \\ ISSN 1679-9860}

O significado da palavra "reforma" nos remete a um conjunto de transformações mais profundas nas discussões acerca da reforma agrária, que são: as políticas públicas, a participação dos trabalhadores, as pesquisas no campo voltadas para a agricultura familiar ligada aos movimentos sociais, assistência técnica, apoio financeiro e distribuição de terras. As políticas de assentamentos são meros reflexos de distribuição de terra pressionados pelos trabalhadores Sem-Terra. Estes assentamentos são mal localizados e sem nenhuma comunicação entre os demais dificultando a melhoria desses espaços, pois a maioria está "ilhada" no meio dos espaços do agronegócio. Isso dificulta o seu desenvolvimento com base em uma agropecuária alternativa aos pacotes tecnológicos do grande capital, pois estando próximos serão levados a consumir estes pacotes.

Para se falar em reforma agrária é preciso que exista - de fato - uma política nesse sentido, um plano com objetivos e metas para a desconcentração fundiária. O governo tem tentado solucionar conflitos no campo com algumas desapropriações e com a compra de terra, respondendo às pressões das famílias sem-terra. Se as famílias não ocuparem a terra, não há assentamento. Ao denominar a atual política de assentamentos de reforma agrária, ignora-se a história da luta pela terra e respectivamente seus protagonistas [...] assentamento implantado como resultado de ocupação é luta pela terra [...] (FERNANDES, 2001: 44).

Segundo Fernandes (1999) o início da ditadura no Brasil não significa, somente a troca de um governo democrático para um governo de militares e sim também outros motivos, como: abafar a luta dos trabalhadores rurais e dos coronéis latifundiários. Pois, o governo dos militares necessitava de bastante força e poder para implantar as suas ações, sendo assim, precisava aniquilar todas as forças contrárias. Em 1965 foi instituído o Sistema Nacional de crédito rural com intuito de modernizar o campo através da inserção de tratores, implementos e insumos agrícolas, ou seja, o desenvolvimento do capitalismo industrial no campo. Só que esse processo deu-se com o benefício dos latifundiários da região Centro-Sul; e também com as grandes empresas e com os grandes projetos de colonização, principalmente, na região Norte e Centro-oeste com os filhos de pequenos agricultores da região Sul impossibilitados de dividir ou de continuar trabalhando nos pequenos minifúndios.

[...] são incentivadores da violência, para fazer valer seu poder ilegítimo, por exemplo, os latifundiários grileiros da UDR - União Democrática Ruralista -, ao mesmo tempo em que atuam no campo fazendo aumentar a violência, atuam decididamente também nas 


\section{GEOAMBIENTE ON-LINE \\ Revista Eletrônica do Curso de Geografia do Campus Jataí - UFG www.jatai.ufg.br/geo/geoambiente \\ | Jataí-GO | n.7 | jul-dez/2006 || ISSN 1679-9860}

cidades, fazendo seu marketing político e suas manifestações [...] (OLIVEIRA, 2001, p.27).

Os grandes produtores uniram-se em prol do predomínio do latifúndio através do braço político da União Democrática Ruralista -UDR - recrudescendo todas as ações acerca deste plano. Inclusive usando do apoio institucional do Estado através da militarização e judiciarização e também de forma ilegal com a presença de jagunços no campo para a proteção do latifúndio concentrador, excludente, expropriador e poupador de mão - de - obra.

Mas, apesar da mudança política dos governantes pela redemocratização não há execução de políticas públicas no campo para os trabalhadores rurais Sem-Terra, o que ocorre é uma política de assentamentos fruto de ocupações e de pressão dos movimentos sociais rurais. Para arrefecer o poder de pressão dos movimentos foi instituída após a década de 1990 a militarização e a judiciarização para barrar a luta pela terra e pela reforma agrária.

[...] No primeiro governo da nova república foi criado o Plano Nacional de reforma agrária, que não se concretizou. A maior parte dos assentamentos implantados durante esse governo foi resultado das ocupações [...] nos governos Collor e Itamar, as políticas criadas para tratar da questão agrária mantiveram a repressão aos Sem-terra [...] a militarização da questão agrária tem sido uma cerca à luta dos trabalhadores. Na década de 90 emergiu uma nova cerca: a judiciarização da luta pela terra, representada pela intensificação da criminalização das ocupações e na contínua impunidade dos mandantes e assassinos dos trabalhadores (FERNANDES, 2001: 20).

No governo de FHC a política neoliberal foi definida pelo banco mundial e consenso de Washington através dos seguintes pontos: privatização, abertura de mercado, terceirização, banco da terra, cadastramento de terra pelo correio, punição das ocupações, extinção do PROCERA (Programa de Créditos para a Reforma Agrária) e Lumiar e implantação do PRONAF (Programa Nacional de Assistência a Agricultura Familiar). Essa articulação enfraqueceu a luta pela terra dos movimentos sociais dos Sem-terra e fortaleceu a reforma agrária de mercado. O PROCERA era um programa específico dos assentamentos de reforma agrária com sua extinção desestruturou o poder de decisão dos movimentos sociais na construção de políticas públicas para esse segmento. O governo de forma autoritária e sem a participação dos trabalhadores rurais instituiu o PRONAF para todo o segmento da agricultura familiar, tanto aos agricultores ligados a CONTAG/CUT (Confederação Nacional dos Trabalhadores na Agricultura/Central Única dos Trabalhadores) mais atrelados ao mercado 


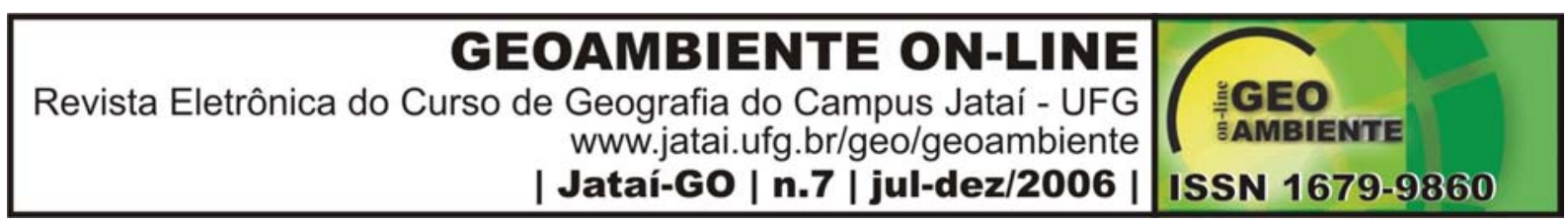

quanto os agricultores regidos pelos movimentos sociais rurais com base na agropecuária alternativa.

[...] "sem a realização da reforma agrária, as ocupações, os assentamentos e a concentração fundiária crescem" [...] (FERNADES, 2001: 23). Os países desenvolvidos que se tornaram desenvolvidos optaram desde o começo pela pequena produção familiar camponesa e mais tarde essas pequenas produções se modernizaram, mas sem concentrar em latifúndios. Fica claro em Fernandes (2001), Guanzirolli (2001) e Oliveira (2001) que o latifúndio é sinal de aumento de pobreza, desigualdade, miséria, exclusão e por fim de subdesenvolvimento. O Brasil do latifúndio é rico, privilegiado, moderno e o Brasil dos trabalhadores Sem-Terra, da agricultura familiar e dos assentamentos rurais é tida como pobre, arcaica, atrasada e sem futuro para os seus integrantes.

\section{A Modernização, o estatuto da terra, o estatuto dos trabalhadores rurais e os subsídios: Um prato cheio para o latifúndio.}

Para Guanziroli. et. al (2001) fica claro que a institucionalização do estatuto ${ }^{2}$ dos trabalhadores rurais piorou a situação dos trabalhadores rurais no campo, principalmente, dos permanentes. Pois, os fazendeiros tinham que pagar os gastos sociais aumentando os custos e por conseqüência a demissão dos trabalhadores rurais.

Com o intuito de acelerar o desenvolvimento do capitalismo no campo, incentivando a reprodução da propriedade capitalista, durante os governos militares pós-64, foram criadas as condições necessárias para o desenvolvimento de uma política agrária, privilegiando as grandes empresas, mediante incentivos financeiros, que passaram a se ocupar da agropecuária [...] o golpe militar de 1964 teve, entre outros objetivos, a finalidade de isolar parcialmente, de um lado, o poder dos coronéis latifundistas e, de outro, impedir totalmente o crescimento das lutas dos trabalhadores rurais, que vinham construindo suas formas de organização [...] a partir de meados da década de cinqüenta (FERNANDES, 1999: 32).

Segundo Fernandes (1999) houve no início do período militar, várias modificações e intervenções nas políticas agrárias, nos órgãos e institutos de desenvolvimento agrário. Só que

\footnotetext{
2 Este estatuto foi instituído para estender as garantias sociais dos trabalhadores do meio urbano às populações rurais. As garantias sociais são: carteira de trabalho regida pela CLT, aposentadorias, a possibilidade do usucapião e outros benefícios aos trabalhadores rurais. Essa garantia do homem do campo não foi integralmente aceitas pela elite rural, acontecendo várias demissões no campo.
} 


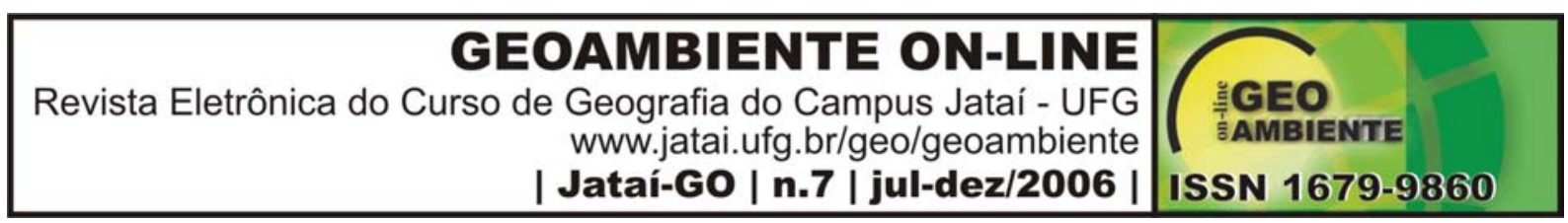

essas intervenções constituíam-se em fachadas para encobrir uma estratégia geopolítica de controle das riquezas naturais do país por grupos nacionais e internacionais. Esta situação possibilitava e dava sustentação aos incentivos fiscais na agricultura brasileira. E ainda, beneficiou grandes empresas agrícolas nas regiões Centro-Oeste e Norte atrelado aos grandes projetos de colonização do período militar. Após 1970 com a institucionalização do Instituto Nacional de Colonização e Reforma Agrária - INCRA - e o Programa de Integração Nacional - PIN - foram fortalecidos, ainda mais, os grandes grupos econômicos do setor agropecuário.

[...] os governos militares estiveram no poder, garantiram a apropriação, por grandes grupos empresariais, de imensas áreas de terras e também o aumento do número e de extensão dos latifúndios. Financiaram as mudanças na base técnica de produção, com base nos incentivos criados e do crédito subsidiado pela sua política agrícola. Proporcionaram assim a modernização da agricultura e a territorialização do capital no campo. Do outro lado, reprimiu toda e qualquer luta de resistência a sua política (FERNANDES, 1999: 39).

De acordo com Fernandes (1999) que destaca a intenção política do Estatuto da terra desde a sua implantação em 1964, que era beneficiar o grande capital monopolista no campo, está claro, na implantação dos grandes projetos agropecuários via mega empresas na Amazônia. Já no Centro-Sul e Nordeste houve uma intensificação da industrialização na agricultura. Esse privilégio do capital monopolista na agricultura faz acentuar a concentração de terras, a expropriação e a exploração. Nessa conjuntura instauram-se vários conflitos em torno da terra.

\section{Uma avaliação da agricultura camponesa e da agricultura familiar.}

Segundo Fernandes (2001) o principal sentido da palavra "camponês" está na luta pela terra e na persistência em não se transformar em um proletário rural. $\mathrm{O}$ capitalismo tenta a todo o momento destruir e arruinar as estruturas camponesas no espaço rural.

[...] a existência do campesinato é conseqüência da sua luta heróica contra a expropriação e a proletarização, causada pelo desenvolvimento do capitalismo, no movimento de criação e recriação do campesinato no processo de diferenciação [...] a formação do campesinato acontece simultaneamente pela exclusão/inclusão das condições de realização do trabalho familiar, criação/destruição/recriação das relações sociais como a 


\section{GEOAMBIENTE ON-LINE \\ Revista Eletrônica do Curso de Geografia do Campus Jataí - UFG www.jatai.ufg.br/geo/geoambiente \\ | Jataí-GO | n.7 | jul-dez/2006 || ISSN 1679-9860}

propriedade camponesa, a posse, o arrendamento, a meação e a parceria [...] (FERNANDES, 2001: 30).

Na década de 1990, principalmente, no governo de Fernando Henrique Cardoso houve uma mudança significativa nas políticas públicas que dão sustentação aos agricultores familiares ligados aos movimentos sociais. Os assentados e acampados até 1995 dispunham de políticas públicas específicas - PROCERA -, mas a partir de 1996 o PROCERA foi extinto e criou-se em seu lugar o PRONAF que veio para atender todo o universo da agricultura familiar tanto aos agricultores ligados aos movimentos sociais como os agricultores ligados a CONTAG/CUT. Com essa mudança tirou-se o poder dos movimentos sociais em propor políticas específicas para os assentamentos e acampamentos ficando esse poder nas mãos do governo.

O objetivo político dos governos ao modificar as regras do jogo no meio da partida é para desestruturar a luta e a força dos movimentos sociais. E a partir dessas mudanças imporem o seu modo de jogar através de novas políticas e de novas condutas e isso é fácil no Brasil, pois não há planejamento com base em políticas públicas de estado e sim de governos. Os governos no Brasil se preocupam, com políticas compensatórias de cunho eleitoreiras e não com políticas públicas de estado com o intuito de amenizar as mazelas rurais do país.

[...] a agricultura familiar vem sendo acometida por políticas agrícolas, que contribuem para com a sua desestruturação, ao passo que a luta pela terra e a luta pela reforma agrária permanecem como condições de enfrentamento e de resistência a um modelo único de desenvolvimento da agricultura. No governo Fernando Henrique Cardoso, a reforma agrária foi apresentada como uma medida para o desenvolvimento da agricultura familiar, para a solução do problema da segurança alimentar e para a redução dos conflitos agrários. Contudo, o projeto se limita a uma política compensatória, sem ter o objetivo de alterar o modelo de desenvolvimento da agricultura (FERNANDES, 1999: 63-64).

Para Fernandes (1999) os agricultores familiares ligados aos movimentos sociais foram acometidos com as mudanças nas políticas públicas, mas não foi na luta pela terra e pela reforma agrária. O principal intuito dessas mudanças estava no objetivo do governo de FHC de empreender um "novo mundo rural" baseado no capital e no mercado fundiário de terras, pelo "banco de terras" e nos assentamentos regidos no mercado de terras, ou seja, o governo (INCRA) compra a terra do latifundiário pelo valor de mercado. A reforma agrária no sentido 


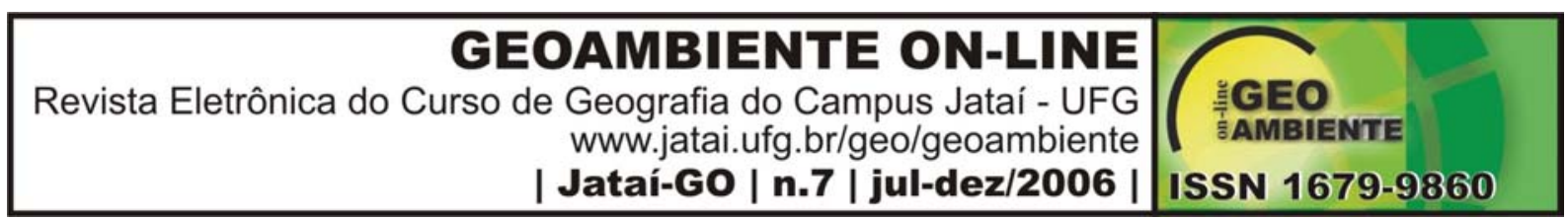

máximo da palavra seria uma mudança ampla na propriedade da terra através de uma divisão em pequenas propriedades.

\section{Considerações Finais}

Então, fica clara a real situação do país face aos problemas sociais no campo. Esse processo é fruto de escassas políticas públicas e heranças coloniais, como os privilégios ao latifúndio. Para solucionar esta questão agrária será preciso além de vontade política, também cidadania, investimento em educação, tecnologia e justiça social.

A questão agrária no campo não se restringe, somente, ao espaço rural abrange também às relações sociais urbanas. Pois a cidade congrega a política, o mercado, a bolsa de cereais e o processo industrial que juntos formam o motor de impulso das atividades no campo. No Brasil falta a interação destes elementos, ou seja, as políticas públicas de Estado com os investimentos públicos e a prioridade da pequena e média propriedade. Além disso, podemos definir que o impasse no campo brasileiro abrange desde a produção agrícola, mas abarca as questões sociais (habitacionais, sobrevivência), ambientais, culturais e políticas. Só resolveremos este problema no todo, com políticas públicas, a participação dos envolvidos no processo e toda a sociedade brasileira de uma forma mais ampla.

\section{Referências Bibliográficas}

FERNANDES, Bernardo Mançano. MST: Formação e territorialização. 2. ed. São Paulo: Hucitec. 285p. 1999.

Questão Agrária, Pesquisa e MST. São Paulo: Cortez, (Coleção Questões da Nossa Época; v. 92). 120p. 2001.

GUANZIROLI, Carlos. et. al. Agricultura Familiar e reforma agrária no século XXI. Rio de Janeiro: Garamond. 288p. 2001.

OLIVEIRA, Ariovaldo Umbelino de. A agricultura camponesa no Brasil. 4. ed. São Paulo: Contexto, 164p. 2001. 